\title{
Identificação de situações e condutas bioéticas na atuação profissional em saúde
}

Edison Vitório de Souza ${ }^{1}$, Gabriel Aguiar Nunes ${ }^{2}$, Cristiane dos Santos Silva ${ }^{3}$, Benedito Fernandes da Silva Filho ${ }^{2}$, Poliana Souza Lapa ${ }^{2}$, Paloma Dias Duarte ${ }^{2}$, Eduardo Nagib Boery ${ }^{2}$, Rita Narriman Silva de Oliveira Boery ${ }^{2}$, Namie Okino Sawada ${ }^{4}$

1. Universidade de São Paulo, Ribeirão Preto/SP, Brasil. 2. Universidade Estadual do Sudoeste da Bahia, Jequié/BA, Brasil.

3. Universidade Norte do Paraná, Londrina/PR, Brasil. 4. Universidade Federal de Alfenas, Alfenas/MG, Brasil.

\section{Resumo}

O objetivo deste estudo foi identificar na literatura situações e condutas bioéticas na atuação profissional em saúde. Trata-se de revisão integrativa de artigos científicos indexados nas bases de dados da Biblioteca Virtual em Saúde e publicados entre 2014 e 2019. Utilizaram-se os descritores "pessoal de saúde", "prática profissional", "ética profissional", "discurso" e "bioética". Foram selecionados 21 estudos para a discussão, destacando-se cinco categorias de análise: bioética durante a formação profissional; bioética como forma de humanizar a saúde; relações interprofissionais, direitos e deveres de trabalhadores e pacientes; bioética nas decisões que permeiam o início e o fim da vida; e tomada de decisões na saúde. A autonomia do paciente foi o princípio bioético mais abordado em diversas circunstâncias clínicas, especialmente nos dilemas relativos ao fim da vida.

Palavras-chave: Saúde pública. Saúde. Bioética. Códigos de ética. Competência profissional. Prática profissional. Direitos humanos.

\section{Resumen}

\section{Identificación de situaciones y conductas bioéticas en la práctica profesional en salud}

El objetivo de este estudio fue identificar en la literatura situaciones y conductas bioéticas de la práctica profesional en salud. Se trata de una revisión integradora de artículos científicos indexados en las bases de datos de la Biblioteca Virtual en Salud, publicados entre 2014 y 2019. Se utilizaron los descriptores "personal de salud", "práctica profesional", "ética profesional", "discurso" y "bioética". Se seleccionaron 21 estudios para discusión y, del análisis, surgieron cinco categorías: bioética durante la formación profesional; bioética como forma de humanizar la salud; relaciones interprofesionales, derechos y deberes de los trabajadores y pacientes; bioética en las decisiones que permean el inicio y el final de la vida; y toma de decisiones en salud. La autonomía del paciente fue el principio bioético más abordado en diversas circunstancias clínicas, especialmente en los dilemas al final de la vida.

Palabras clave: Salud pública. Salud. Bioética. Códigos de ética. Competencia profesional. Práctica profesional. Derechos humanos.

\section{Abstract \\ Evidence of bioethical discourse and behaviors in health professions}

This study aimed to identify bioethical situations and behaviors in health professions reported in the literature. This integrative review of scientific articles indexed in the Virtual Health Library databases, published between 2014 and 2019, used the following keywords: "health personnel," "professional practice," "ethics, professional," "discourse," and "bioethics." Twenty-one studies were selected for discussion, with five categories identified in the analysis: bioethics during professional training; bioethics as a form of humanizing healthcare; interprofessional relationships, rights and duties of patients and professionals; bioethics in decisions in the beginning and end of life; and decision making in healthcare. Patient autonomy was the bioethical principle most often addressed in various clinical circumstances, especially in end-of-life dilemmas.

Keywords: Public health. Health. Bioethics. Codes of ethics. Professional competence. Professional practice. Human rights. 
A bioética é entendida como campo interdisciplinar, pluralista e não corporativista que foca questões relacionadas à vida humana, delineando princípios em defesa da vida, da saúde e do meio ambiente ${ }^{1-3}$. Foi descrita inicialmente na década de 1970, quando o oncologista Van Rensselaer Potter ${ }^{4}$ reconheceu que nem sempre a totalidade das coisas cientificamente exequíveis era moralmente correta, adotando o vocábulo "bioética". Com o passar dos anos, o termo se tornou essencial para a comunicação entre as diversas áreas de conhecimento, abrangendo concepções éticas, morais, religiosas, técnicas, científicas, entre outras, no intuito de propor, descrever e apreciar estratégias para garantir a proteção de todos os sujeitos ${ }^{5}$.

A bioética se fundamenta em quatro princípios: autonomia, beneficência, não maleficência e justiça. A autonomia diz respeito ao consentimento, à capacidade de pensar e agir, traduzindo-se na prática pessoal de autogoverno; a beneficência propõe minimizar riscos e maximizar benefícios; a não maleficência objetiva evitar danos previsíveis; e, por fim, a justiça diz respeito à equidade na concessão de bens e/ou benefí$\operatorname{cios}^{1,3}$. Desse modo, considerando o reconhecimento de Potter ${ }^{4}$ na década de 1970 , é relevante aprofundar os estudos sobre bioética entre as práticas profissionais das equipes de saúde. Nessa perspectiva, objetivou-se, neste estudo, identificar na literatura as situações e condutas bioéticas na atuação profissional em saúde.

\section{Método}

Trata-se de revisão integrativa de literatura, método científico cuja finalidade é sintetizar de forma abrangente e sistemática o resultado de pesquisas de diversos tipos, incluindo dados empíricos e teóricos ${ }^{1,6}$. Adotaram-se seis etapas sequenciais e interdependentes na sistematização do percurso metodológico: identificação do tema e seleção da questão de pesquisa; busca na literatura com aplicação dos critérios de inclusão e exclusão; definição das informações a serem extraídas dos estudos selecionados; avaliação dos estudos incluídos na revisão integrativa; interpretação dos resultados; e síntese do conhecimento ${ }^{7}$. Desse modo, esta revisão integrativa se dedicou a responder a seguinte questão de pesquisa: em quais contextos se identificam na literatura situações e condutas bioéticas na atuação do profissional de saúde?

A revisão se baseou na pesquisa de artigos científicos indexados nas bases de dados da Biblioteca Virtual em Saúde ${ }^{8}$, adotando-se oito combinações de cinco termos contidos nos Descritores em Ciências da Saúde: "pessoal de saúde"; "prática profissional"; "ética profissional"; "discurso"; e "bioética". Todas as combinações estiveram atreladas ao descritor "pessoal de saúde" com o objetivo de restringir a busca e evitar a inclusão de estudos desenvolvidos com outras classes profissionais (Quadro 1). Ressalta-se que se utilizou entre os descritores em cada combinação o operador booleano "and", no intuito de serem destacados pelo portal apenas artigos com abordagens similares.

Adotaram-se os seguintes critérios de inclusão: artigos disponíveis gratuitamente para download, publicados entre 2014 e 2019, sem restrições de idioma e com enfoque em discursos e condutas bioéticas nas profissões da saúde. Depois de os critérios de inclusão terem sido aplicados, os artigos remanescentes foram lidos para identificar se de fato se relacionavam ao objeto deste estudo. Foram, com isso, selecionados 21 artigos $^{2,5,9-27}$, todos direcionados à temática da bioética no campo de atuação de profissionais enfermeiros e/ou médicos.

Os artigos selecionados foram em seguida avaliados por meio de leitura crítico-reflexiva aprofundada, da qual emergiram cinco categorias para nortear a discussão: bioética durante a formação profissional ${ }^{10,15,17,19,23}$; bioética como forma de humanizar a saúde ${ }^{9,15,21}$; relações interprofissionais, direitos e deveres de trabalhadores e pacientes ${ }^{13-16,18,20,22,26}$; bioética nas decisões que permeiam o início e o fim da vida 2,5,12,14,16,17,25-27; e tomada de decisões na saúde ${ }^{11,12,19,24}$.

Ressalta-se que, devido ao delineamento metodológico, não foi preciso submeter o estudo à apreciação do Comitê de Ética em Pesquisa, conforme a Resolução 510/2016 do Conselho Nacional de Saúde ${ }^{28}$. 
Quadro 1. Combinações de descritores para subsidiar a busca de artigos na Biblioteca Virtual em Saúde

\begin{tabular}{|c|c|c|c|c|c|c|c|}
\hline Combinações & Descritor 1 & Descritor 2 & Descritor 3 & Descritor 4 & Descritor 5 & $\begin{array}{l}\text { Total de } \\
\text { artigos* }\end{array}$ & $\begin{array}{c}\text { Total de } \\
\text { artigos** }^{*}\end{array}$ \\
\hline 1 & $\begin{array}{l}\text { Pessoal de } \\
\text { saúde }\end{array}$ & $\begin{array}{l}\text { Prática } \\
\text { profissional }\end{array}$ & $\begin{array}{l}\text { Ética } \\
\text { profissional }\end{array}$ & Discurso & Bioética & 3 & 0 \\
\hline 2 & $\begin{array}{l}\text { Pessoal de } \\
\text { saúde }\end{array}$ & $\begin{array}{l}\text { Prática } \\
\text { profissional }\end{array}$ & $\begin{array}{l}\text { Ética } \\
\text { profissional }\end{array}$ & Discurso & - & 16 & $2^{9,10}$ \\
\hline 3 & $\begin{array}{l}\text { Pessoal de } \\
\text { saúde }\end{array}$ & $\begin{array}{l}\text { Prática } \\
\text { profissional }\end{array}$ & $\begin{array}{l}\text { Ética } \\
\text { profissional }\end{array}$ & - & Bioética & 49 & $7^{2,11-16}$ \\
\hline 4 & $\begin{array}{l}\text { Pessoal de } \\
\text { saúde }\end{array}$ & $\begin{array}{l}\text { Prática } \\
\text { profissional }\end{array}$ & - & Discurso & Bioética & 7 & $1^{17}$ \\
\hline 5 & $\begin{array}{l}\text { Pessoal de } \\
\text { saúde }\end{array}$ & $\begin{array}{l}\text { Prática } \\
\text { profissional }\end{array}$ & - & - & Bioética & 74 & $4^{5,18-20}$ \\
\hline 6 & $\begin{array}{l}\text { Pessoal de } \\
\text { saúde }\end{array}$ & - & - & Discurso & Bioética & 16 & 0 \\
\hline 7 & $\begin{array}{l}\text { Pessoal de } \\
\text { saúde }\end{array}$ & - & - & - & Bioética & 1.220 & $7^{21-27}$ \\
\hline 8 & $\begin{array}{l}\text { Pessoal de } \\
\text { saúde }\end{array}$ & - & $\begin{array}{l}\text { Ética } \\
\text { profissional }\end{array}$ & Discurso & Bioética & 5 & 0 \\
\hline
\end{tabular}

*Total de artigos encontrados antes de os critérios de inclusão serem aplicados; **total de artigos selecionados após a aplicação dos critérios de inclusão e leitura prévia dos restantes

\section{Resultados e discussão}

Como demonstra o Quadro 2, os 21 artigos identificados apresentam autores principais distintos, e a maioria dos estudos foi publicada na Revista Bioética ( $\mathrm{n}=14)$. Ressalta-se que o periódico com maior adesão dissemina especificadamente conteúdos relacionados a pesquisas ou vivências no campo da bioética ou da ética médica, correspondendo ao objeto de estudo analisado nesta pesquisa.

A discriminação das principais vertentes tratadas nos estudos revela frequente associação de assuntos complexos, como implementação de assistência humanizada, convívio com a terminalidade da vida e o entendimento dos princípios bioéticos como estratégia de trabalho em situações conflitantes. A bioética também é evidenciada nos estudos como mediadora nas tomadas de decisão e na preservação dos direitos fundamentais, da individualidade de cada envolvido e do respeito mútuo nas relações entre os diversos agentes do processo saúde-doença. Contudo, identifica-se ainda o desconhecimento de aspectos legais concernentes à manutenção da autonomia do paciente na assistência em saúde. Dentre os princípios bioéticos evidenciados, a autonomia foi o mais recorrente na amostra, atrelando-se à democratização do vínculo entre profissionais de saúde e usuários, bem como à valorização do indivíduo no processo terapêutico.

Quadro 2. Artigos selecionados

\begin{tabular}{|c|c|c|c|}
\hline Autoria/ano & Periódico/título do artigo & Principais temas abordados & Princípios bioéticos abordados \\
\hline $\begin{array}{l}\text { ntos e } \\
\text { laboradores; } \\
14^{2}\end{array}$ & $\begin{array}{l}\text { Revista Bioética } \\
\text { "Reflexões bioéticas sobre } \\
\text { a eutanásia a partir de caso } \\
\text { paradigmático" }\end{array}$ & Ilegitimidade da eutanásia & $\begin{array}{l}\text { Beneficência e não } \\
\text { maleficência }\end{array}$ \\
\hline $\begin{array}{l}\text { otta e } \\
\text { laboradores; } \\
16^{5}\end{array}$ & $\begin{array}{l}\text { Revista Bioética } \\
\text { "Tomada de decisão em } \\
\text { (bio)ética clínica: abordagens } \\
\text { contemporâneas" }\end{array}$ & $\begin{array}{l}\text { Complexidade da tomada } \\
\text { de decisões profissionais no } \\
\text { âmbito da saúde }\end{array}$ & Autonomia \\
\hline
\end{tabular}

continua... 
Quadro 2. Continuação

\begin{tabular}{|c|c|c|c|}
\hline Autoria/ano & Periódico/título do artigo & Principais temas abordados & Princípios bioéticos abordados \\
\hline $\begin{array}{l}\text { Seoane, Fortes; } \\
2014^{9}\end{array}$ & $\begin{array}{l}\text { Saúde e Sociedade } \\
\text { "Percepção de médicos e } \\
\text { enfermeiros de unidades } \\
\text { de assistência médica } \\
\text { ambulatorial sobre } \\
\text { humanização nos } \\
\text { serviços de saúde" }\end{array}$ & $\begin{array}{l}\text { Diversidade de significados } \\
\text { atribuídos à humanização } \\
\text { pelos profissionais de saúde }\end{array}$ & Autonomia \\
\hline $\begin{array}{l}\text { Franco e } \\
\text { colaboradores; } \\
2014^{10}\end{array}$ & $\begin{array}{l}\text { Revista Brasileira de Educação } \\
\text { Médica } \\
\text { "O conceito de competência: } \\
\text { uma análise do discurso } \\
\text { docente" }\end{array}$ & $\begin{array}{l}\text { Aplicabilidade de saberes } \\
\text { e condutas relacionadas à } \\
\text { prática baseada em preceitos } \\
\text { éticos e reflexivos }\end{array}$ & Autonomia \\
\hline $\begin{array}{l}\text { Siqueira-Batista } \\
\text { e colaboradores; } \\
2014^{11}\end{array}$ & $\begin{array}{l}\text { Revista Bioética } \\
\text { "Modelos de tomada de } \\
\text { decisão em bioética clínica: } \\
\text { apontamentos para a } \\
\text { abordagem computacional" }\end{array}$ & $\begin{array}{l}\text { Caracterização e suporte } \\
\text { do processo decisório em } \\
\text { bioética clínica }\end{array}$ & Autonomia \\
\hline $\begin{array}{l}\text { Eich, Verdi, Martins; } \\
2015^{12}\end{array}$ & $\begin{array}{l}\text { Revista Bioética } \\
\text { "Deliberação moral em } \\
\text { sedação paliativa para uma } \\
\text { equipe de cuidados paliativos } \\
\text { oncológicos" }\end{array}$ & $\begin{array}{l}\text { Uso racional da sedação } \\
\text { paliativa como método de } \\
\text { reduzir o sofrimento no } \\
\text { processo de morte e morrer }\end{array}$ & Autonomia e não maleficência \\
\hline $\begin{array}{l}\text { Gomes, Ramos; } \\
2015^{13}\end{array}$ & $\begin{array}{l}\text { Interface - Comunicação, } \\
\text { Saúde, Educação } \\
\text { "Solidariedade, aliança } \\
\text { e comprometimento do } \\
\text { profissional da saúde nas } \\
\text { práticas do Sistema Único } \\
\text { de Saúde (SUS): um debate } \\
\text { bioético" }\end{array}$ & $\begin{array}{l}\text { Ampliação de espaços para } \\
\text { debate bioético visando } \\
\text { intensificar o diálogo e } \\
\text { mudar valores relacionados } \\
\text { ao usuário, ao profissional, } \\
\text { à sociedade e aos serviços } \\
\text { de saúde }\end{array}$ & Beneficência e autonomia \\
\hline Gracindo; $2015^{14}$ & $\begin{array}{l}\text { Revista Bioética } \\
\text { "A moralidade das } \\
\text { intervenções cirúrgicas com } \\
\text { fins estéticos de acordo com a } \\
\text { bioética principialista" }\end{array}$ & $\begin{array}{l}\text { Direitos e deveres do } \\
\text { paciente e do profissional } \\
\text { de saúde em intervenções } \\
\text { cirúrgicas estéticas }\end{array}$ & Autonomia \\
\hline Saito, Zoboli; $2015^{15}$ & $\begin{array}{l}\text { Revista Bioética } \\
\text { "Cuidados paliativos e a atenção } \\
\text { primária à saúde: scoping } \\
\text { review" }\end{array}$ & $\begin{array}{l}\text { Problemas éticos e requisitos } \\
\text { para incorporação dos cuidados } \\
\text { paliativos na atenção primária }\end{array}$ & Autonomia \\
\hline $\begin{array}{l}\text { Chehuen Neto e } \\
\text { colaboradores; } \\
2015^{16}\end{array}$ & $\begin{array}{l}\text { Revista Bioética } \\
\text { "Testamento vital: o que } \\
\text { pensam profissionais de } \\
\text { saúde?" }\end{array}$ & $\begin{array}{l}\text { Desconhecimento profissional } \\
\text { sobre o testamento vital } \\
\text { aplicado à assistência em saúde }\end{array}$ & Autonomia \\
\hline $\begin{array}{l}\text { Guimarães e } \\
\text { colaboradores; } \\
2016^{17}\end{array}$ & $\begin{array}{l}\text { Revista Enfermagem Uerj } \\
\text { "Eutanásia e distanásia: } \\
\text { percepção de médicos e } \\
\text { enfermeiros de uma cidade } \\
\text { sul mineira" }\end{array}$ & $\begin{array}{l}\text { Escassez de discussões e } \\
\text { vivências acerca de eutanásia } \\
\text { e distanásia na formação e } \\
\text { prática profissional em saúde }\end{array}$ & $\begin{array}{l}\text { Beneficência e não } \\
\text { maleficência }\end{array}$ \\
\hline
\end{tabular}

continua... 
Quadro 2. Continuação

\begin{tabular}{|c|c|c|c|}
\hline Autoria/ano & Periódico/título do artigo & Principais temas abordados & Princípios bioéticos abordados \\
\hline $\begin{array}{l}\text { Outomuro, } \\
\text { Mirabile; } 2015^{18}\end{array}$ & $\begin{array}{l}\text { Revista Bioética } \\
\text { "Confidencialidad y privacidad } \\
\text { en la medicina y en la } \\
\text { investigación científica: desde la } \\
\text { bioética a la ley" }\end{array}$ & $\begin{array}{l}\text { Entendimento da privacidade } \\
\text { como norma ética }\end{array}$ & $\begin{array}{l}\text { Autonomia, beneficência e } \\
\text { não maleficência }\end{array}$ \\
\hline $\begin{array}{l}\text { Nora, Zoboli, Vieira; } \\
2015^{19}\end{array}$ & $\begin{array}{l}\text { Revista Bioética } \\
\text { "Deliberação ética em saúde: } \\
\text { revisão integrativa da literatura" }\end{array}$ & $\begin{array}{l}\text { Deliberação como instrumento } \\
\text { de educação permanente e } \\
\text { resolução de problemas }\end{array}$ & Autonomia \\
\hline $\begin{array}{l}\text { Marques Filho, } \\
\text { Hossne; } 2015^{20}\end{array}$ & $\begin{array}{l}\text { Revista Bioética } \\
\text { "A relação médico-paciente } \\
\text { sob a influência do referencial } \\
\text { bioético da autonomia" }\end{array}$ & $\begin{array}{l}\text { Contribuições da autonomia } \\
\text { no desenvolvimento da relação } \\
\text { entre usuário e profissional }\end{array}$ & Autonomia \\
\hline Riveros Ríos; $2017^{21}$ & $\begin{array}{l}\text { Anales de la Facultad de } \\
\text { Ciencias Médicas (Asunción) } \\
\text { "Aspectos bioéticos desde } \\
\text { la visión personalista de la } \\
\text { espiritualidad en el manejo de } \\
\text { las personas en el área de la } \\
\text { salud" }\end{array}$ & $\begin{array}{l}\text { Afirmação dos princípios } \\
\text { fundamentais relacionando } \\
\text { espiritualidade e preceitos éticos }\end{array}$ & $\begin{array}{l}\text { Beneficência e não } \\
\text { maleficência }\end{array}$ \\
\hline $\begin{array}{l}\text { Santos e } \\
\text { colaboradores; } \\
2017^{22}\end{array}$ & $\begin{array}{l}\text { Revista Bioética } \\
\text { "Considerações bioéticas } \\
\text { sobre a relação médico- } \\
\text {-paciente indígena" }\end{array}$ & $\begin{array}{l}\text { Divergência de percepções no } \\
\text { processo de saúde-doença }\end{array}$ & Autonomia \\
\hline $\begin{array}{l}\text { Gomes e } \\
\text { colaboradores; } \\
2016^{23}\end{array}$ & $\begin{array}{l}\text { Revista Bioética } \\
\text { "Estratégia Saúde da Família e } \\
\text { bioética: grupos focais sobre } \\
\text { trabalho e formação" }\end{array}$ & $\begin{array}{l}\text { Centralidade da bioética no } \\
\text { trabalho em unidades de } \\
\text { saúde da família }\end{array}$ & $\begin{array}{l}\text { Beneficência e não } \\
\text { maleficência }\end{array}$ \\
\hline $\begin{array}{l}\text { Fachini, Scrigni, } \\
\text { Lima; } 2017^{24}\end{array}$ & $\begin{array}{l}\text { Revista Bioética } \\
\text { "Sofrimento moral de } \\
\text { trabalhadores de uma UTI } \\
\text { pediátrica" }\end{array}$ & $\begin{array}{l}\text { Capacidade de exercer } \\
\text { autonomia no ambiente } \\
\text { de trabalho }\end{array}$ & Autonomia \\
\hline $\begin{array}{l}\text { Eidt, Bruneri, } \\
\text { Bonamigo; } 2017^{25}\end{array}$ & $\begin{array}{l}\text { O Mundo da Saúde } \\
\text { "Ordem de não reanimar sob } \\
\text { a perspectiva de pacientes } \\
\text { oncológicos e seus familiares" }\end{array}$ & $\begin{array}{l}\text { Conhecimento e adesão à } \\
\text { ordem de não reanimar em } \\
\text { pacientes terminais }\end{array}$ & Autonomia \\
\hline $\begin{array}{l}\text { Pirôpo e } \\
\text { colaboradores; } \\
2018^{26}\end{array}$ & $\begin{array}{l}\text { Revista de Salud Pública } \\
\text { "Interface do testamento } \\
\text { vital com a bioética, atuação } \\
\text { profissional e autonomia do } \\
\text { paciente" }\end{array}$ & $\begin{array}{l}\text { Conhecimento dos } \\
\text { profissionais de saúde acerca } \\
\text { dos direitos individuais e da } \\
\text { autonomia do paciente em } \\
\text { fase terminal }\end{array}$ & Autonomia \\
\hline $\begin{array}{l}\text { Brandalise e } \\
\text { colaboradores; } \\
2018^{27}\end{array}$ & $\begin{array}{l}\text { Revista Bioética } \\
\text { "Suicídio assistido e eutanásia } \\
\text { na perspectiva de profissionais } \\
\text { e acadêmicos de um hospital } \\
\text { universitário" }\end{array}$ & $\begin{array}{l}\text { Conhecimento e aceitação } \\
\text { da eutanásia e do suicídio } \\
\text { assistido por parte de } \\
\text { profissionais e graduandos da } \\
\text { área da saúde }\end{array}$ & Autonomia \\
\hline
\end{tabular}




\section{Bioética durante a formação profissional}

Instituições de ensino devem promover ampla discussão sobre atributos éticos e morais com alunos e sociedade ${ }^{10}$. Além disso, questões éticas não podem ser enfrentadas normativamente, como se houvesse fórmulas prontas, pois precisam ser debatidas de forma criativa para identificar novas estratégias de solução ${ }^{19}$. Tratando-se da bioética, os argumentos devem ser analisados considerando seres humanos, meio ambiente e seres vivos em geral, sob ótica complexa e multidimensional. A bioética deve ser vivenciada e praticada, ainda, por meio de ações que estimulem o saber prático e humanizado ${ }^{10}$.

Nessa perspectiva, um estudo identificou que o ensino da temática é capaz de potencializar as condutas avaliativas dos estudantes em formação, que passam a demonstrar maior habilidade profissional em perspectiva biopsicossocial, holística, no empoderamento de pacientes, na responsabilização e na adesão terapêutica, aumentando satisfatoriamente a qualidade da assistência prestada ${ }^{10}$. Outro estudo, realizado em Viçosa/MG com equipe de saúde da família, observou que os profissionais têm muita dificuldade em conceituar ética e bioética ${ }^{23}$. Constatou, entretanto, desejo geral de buscar conhecimentos sobre o tema, dada a sua importância, além de a imprescindibilidade de criar espaços para formação e debates sobre problemas bioéticos ter sido reconhecida ${ }^{23}$.

Outro contexto encontrado foi a deficiência na comunicação entre profissionais, pacientes e familiares, observada em estudo realizado no Brasil ${ }^{15}$, sendo os resultados atribuídos a deficiência na formação acadêmica. A comunicação é considerada instrumento estratégico de gestão e pode empoderar pacientes e familiares no exercício de sua autonomia e, ao mesmo tempo, possibilitar a troca de conhecimentos entre membros da equipe no intuito de assegurar a melhor conduta terapêutica, incluindo os aspectos bioéticos envolvidos. Fato é que falhas na comunicação inviabilizam o debate e a conduta segundo preceitos bioéticos, assim como a adição de informações para o exercício da cidadania em procedimentos terapêuticos e assistenciais.

A comunicação se fez presente também na exposição de condutas que aliviam o sofrimento de pacientes e familiares, contemplando ainda a divulgação de más notícias, como diagnóstico complexo ou necessidade de limitação terapêutica e tomada de decisão diante de padecimento e morte iminente, como no caso da eutanásia. Vale mencionar que a eutanásia é apontada como prática oposta ao exercício ético da medicina ${ }^{2}$, sendo considerada crime na legislação brasileira, enquadrando-se como homicídio conforme o artigo 121 do Código Penal ${ }^{29}$, com prisão prevista de 2 a 4 anos ${ }^{17}$.

Situações conflitantes vivenciadas em casos terminais levam os profissionais a questionar o preparo recebido nas instituições de ensino. Desse modo, as escolas médicas devem ampliar o debate sobre a temática durante a formação profissional, uma vez que no Brasil ainda não há contextos válidos nos quais incorrem a prática de eutanásia ou a implementação da distanásia como método assistencial. Além disso, o conhecimento adquirido não é suficiente para eliminar o sofrimento dos pacientes, limitando-se muitas vezes ao cuidado físico, o que rompe a integralidade da assistência ${ }^{17}$.

Não obstante, o ambiente hospitalar também carece de meios para discutir eutanásia. Ressalta-se que, para algumas culturas, a morte representa algo negativo, e a maioria dos profissionais não está preparada para enfrentar tal situação. Na percepção dos enfermeiros, a formação profissional muito influencia esse quesito, pois geralmente foca em salvar vidas, não aceitar a morte. Como consequência, o profissional sente frustração, sofrimento e angústia quando se depara com situações envolvendo a temática ${ }^{17}$.

\section{Bioética como forma de humanizar a saúde}

O termo "humanizar" expressa o sentido de "tornar humano", isto é, auxiliar as pessoas e incentivá-las a realizar seus desejos de forma digna. É conceito amplo que busca compreender cada pessoa e suas necessidades e peculiaridades, fornecendo condições para que exerçam seus anseios de forma autônoma 9. Estudo observou que os profissionais de saúde se preocupam com questões referentes à autonomia dos pacientes, principalmente por reconhecerem a importância da comunicação na efetividade do processo de autogoverno e corresponsabilidade?

Convém elencar os cuidados paliativos e a espiritualidade como assuntos que envolvem a bioética 
e a humanização da saúde. Os cuidados paliativos objetivam melhorar a qualidade de vida de pessoas em fase terminal ou que vivem com alguma doença crônico-degenerativa. São projetos terapêuticos elaborados por equipe multiprofissional e que devem ser oferecidos em todos os pontos da rede de atenção à saúde, em seus diferentes níveis de complexidade. Visando à beneficência e à não maleficência, propõe-se que os cuidados paliativos sejam implementados o mais precocemente possível, e não somente em casos terminais ${ }^{15}$.

No entendimento biomédico, a dimensão somática é a mais relevante em cuidados paliativos, e não os aspectos psicossociais e espirituais. Tal percepção explica a rara cooperação com agentes religiosos e a resistência em discutir espiritualidade com os pacientes ${ }^{30}$. Além dos médicos, enfermeiros também relatam não se sentir aptos a abordar tais assuntos, ainda que reconheçam a relevância dos aspectos espirituais e religiosos na fase final da vida ${ }^{31}$.

Nessa perspectiva, cita-se o caso de criança indígena que sofreu acidente ofídico e foi hospitalizada em pronto-socorro na cidade de Manaus/AM em $2009^{32}$. O pai da vítima solicitou que o pajé de sua tribo fosse autorizado a entrar na unidade de saúde para tratar a criança conforme suas práticas culturais; no entanto, teve o pedido negado. Exerceu então seu direito à autonomia e conseguiu na Justiça, embasado nos direitos humanos, que sua filha fosse liberada do hospital, transferindo-a a uma casa de saúde indígena para que pudesse ser tratada ao modo de sua tribo. Posteriormente, o diretor do hospital entrou em contato e propôs tratamento conjunto. Três dias após a conciliação das terapias científicas, empíricas e espirituais, a criança evoluiu para normotermia, obtendo melhora extremamente significativa na cicatrização do membro afetado, o que suspendeu a indicação de amputação ${ }^{32}$.

Ressalta-se que todos os aspectos que envolvem a bioética estão relacionados à espiritualidade. Por exemplo, a beneficência pode ser julgada a partir dos benefícios trazidos ao paciente por meio da visão integral, ou seja, considerando o indivíduo também como ser espiritual. A não maleficência minimiza riscos se o contexto espiritual for considerado. A autonomia dá ao indivíduo liberdade religiosa e espiritual para vivenciar e evocar sua crença de forma espontânea ou quando o sofrimento apontar para essa dimensão como forma terapêutica. Por fim, a justiça permite, de forma equitativa, explorar diversos meios terapêuticos, considerando todos os aspectos que permeiam a vida humana, inclusive a espiritualidade ${ }^{21}$.

É importante destacar que em nenhum momento se evidenciou a consideração da autonomia da criança para o exercício de seu direito à vida e à saúde. Diante da doença e hospitalização, o menor de idade geralmente participa passivamente do processo assistencial, dependendo da figura adulta para sua sobrevivência e para o controle sobre vários aspectos relacionados à saúde, o que gera medo, rebeldia, vulnerabilidade, pavor e sentimentos deprimentes. A criança passa a ser considerada capaz de tomar decisões a partir dos 10,6 anos, em média, quando demonstra, em geral, estar apta a exercer a autodeterminação ${ }^{33}$.

\section{Relações interprofissionais, direitos e} deveres de trabalhadores e pacientes

No que diz respeito às relações interprofissionais, um estudo evidenciou falha comunicativa entre médicos e enfermeiros tanto da equipe da atenção primária quanto de profissionais dos diversos serviços que integram a rede de atenção à saúde ${ }^{15}$. Tal afirmação se baseia em reclamações dos médicos da atenção primária de que os especialistas não compartilhavam informações sobre o paciente, impossibilitando o cuidado integral. Já os enfermeiros da atenção primária relataram que os profissionais médicos hesitam em responder às solicitações da equipe de enfermagem, acatar novas iniciativas e atender às necessidades dos pacientes ${ }^{15}$.

Observa-se, desse modo, conflito na relação entre médicos e enfermeiros decorrente da diferença de autoridade das profissões. Nota-se que os enfermeiros consideram os relacionamentos interpessoais mais importantes que a expertise técnica e o saber científico do médico ${ }^{15}$, enquanto médicos avaliam essas relações e aspectos que envolvem negociação menos relevantes ${ }^{16}$. Deve-se considerar, nessa perspectiva, que a formação médica se fundamenta em elementos cientificistas e na biomedicina. Tais disciplinas geralmente não abrangem conteúdos relacionados à antropologia da saúde, contrastando com a formação ético-humanística preconizada pelo Conselho Nacional de Educação ${ }^{34}$. Não obstante, 
a incapacidade de muitos profissionais em responder aos variados conflitos de ordem cultural vivenciados na prática da medicina é em grande parte atribuída a deficiência na formação ${ }^{22}$.

Destaca-se que nas últimas décadas pacientes têm participado cada vez mais frequentemente das decisões terapêuticas, e seu envolvimento é alvo de constantes transformações ${ }^{16,26}$. Tal observância pode estar relacionada com os avanços obtidos nas diretrizes curriculares dos cursos de graduação, visto que nos últimos anos os profissionais vêm demonstrando entender a importância de fortalecer o vínculo com os pacientes que desfrutam de seu trabalho ${ }^{26}$.

Além disso, a bioética como campo do saber manifesta-se como espaço de debates. Como Gomes e Ramos afirmam, em movimento contra-hegemônico frente às injunções individualizantes do modelo contemporâneo de sociedade (...), ampliar espaços de debate bioético parece reforçar a dialogicidade entre paciente-comunidade-profissional-serviço e estimular mudança de valores com incorporação da aliança, [do] comprometimento e [da] solidariedade ${ }^{35}$.

$\mathrm{O}$ relacionamento entre médico e paciente deve se fundamentar nas dimensões técnica, humanística, ética e estética, e sua relevância é tamanha a ponto de só ser possível nomear "ato médico" a ação de profissional que necessariamente resguarde relação satisfatória com seus pacientes ${ }^{20}$. No entanto, estudo evidenciou que é pouco provável que os médicos discutam cuidados paliativos com os pacientes, justamente por acreditarem tratar-se de assunto que demanda tempo ${ }^{15}$. Além disso, apontam que, por ser desconfortável, essa discussão pode não ser benéfica ao paciente ${ }^{15}$, ferindo, com isso, o princípio da não maleficência. Por outro lado, no mesmo estudo os enfermeiros reconhecem a relevância de dialogar sobre a morte com pacientes que não apresentam possibilidades de cura, apesar de só abordarem o tema quando o enfermo está disposto ou quando surge oportunidade ${ }^{15}$.

Outro ponto que merece ser ponderado à luz da bioética é a falta de veracidade ao informar o estado de saúde a pacientes e familiares ${ }^{15}$. Não obstante, estudo apontou quebra de sigilo sobre terapêutica e prognóstico de pacientes em cuidados paliativos ${ }^{15}$. Destaca-se que o direito à privacidade não pode ser internalizado apenas sob a ótica legal, visto que a bioética vem consolidando esforços para constituí-lo como norma ética. As regras que envolvem privacidade estão intimamente relacionadas ao princípio da autonomia ${ }^{18}$, uma vez que o direito à privacidade protege o acesso às informações de acordo com o consentimento do sujeito ativo no processo. Logo, constata-se que a violação da privacidade do paciente fere gravemente sua autonomia ${ }^{18}$, considerada uma das conquistas bioéticas de maior significância do século $X X^{20}$.

Vale ressaltar que a autonomia do paciente é questionável em alguns casos, citando-se como exemplo intervenções cirúrgicas com fins estéticos. Indivíduos têm o direito de fazê-las e escolher o médico responsável pelo procedimento cirúrgico, mas sua autonomia não é absoluta. É dever do profissional esclarecer o interessado sobre riscos e contraindicações, tendo o direito de se negar a executar cirurgias potencialmente lesivas ou danosas à saúde do paciente ${ }^{14}$, cumprindo, desse modo, o princípio da não maleficência.

\section{Bioética nas decisões que permeiam o início e o fim da vida}

Ao abordar o início da vida, um dos assuntos que vêm à tona é a neonatologia. Tratando-se das unidades de terapia intensiva neonatal, notou-se que diversos dilemas bioéticos ali surgidos também estão presentes nas unidades de terapia intensiva para adultos. Dentre tais dilemas destacam-se a tomada de decisão sobre a manutenção artificial das funções vitais, sobre quais recém-nascidos devem ser beneficiados e de que maneira se beneficiarão dos recursos disponíveis, o potencial de prolongar o sofrimento dos neonatos e familiares, entre outros ${ }^{5}$. Uma vez que neonatos não desenvolveram ainda capacidade de autogoverno, sua autonomia é compartilhada com seus familiares, que são amparados legalmente para decidir junto à equipe sobre determinadas condutas ${ }^{5,36}$.

$\mathrm{O}$ aumento da longevidade observado nos últimos anos vem despertando nos profissionais da saúde reflexões sobre até que ponto o prolongamento da vida, às vezes inútil, torna-se lícito, considerando o sofrimento. Nesse segmento, evidencia-se o despreparo de muitos profissionais para refletir e agir quando o próprio paciente pede para morrer, com o intuito de aliviar o sofrimento e a dor ${ }^{26}$. 
A distanásia é prática que prolonga a vida de pacientes sem possibilidade terapêutica de cura e em sofrimento físico, psíquico e/ou emocional. Certamente, tal conduta nessas situações não beneficia o paciente e, de maneira oposta, prolonga desnecessariamente sua angústia e dor, desrespeitando, desse modo, o princípio da beneficência ${ }^{2}$.

O fato é que o debate sobre a vida e a morte apresenta diversos aspectos que envolvem instituições, equipes de saúde, pacientes e familiares, que concomitantemente divergem acerca dos assuntos relacionados ao fim da vida ${ }^{26}$. Entretanto, vale mencionar que quantidade de vida não é sinônimo de qualidade de vida, e os medos e tabus que tratam a morte como inimiga ou incompetência profissional devem ser superados $^{27}$. Nessa perspectiva, surge nova temática capaz de gerar debates extremamente delicados: a eutanásia, termo concebido pelo filósofo Francis Bacon ${ }^{37}$ em 1623. De acordo com sua etimologia, "eutanásia" significa "boa morte" ${ }^{2}$, mas argumenta-se que sua prática nega os princípios da beneficência e não maleficência ${ }^{2}$, o que descaracterizaria seu significado etimológico.

A eutanásia é definida como adoção de meios para pôr fim à vida de indivíduo com doença incurável sem causar-Ihe sofrimento, não se relacionando apenas com a morte, mas com a dignidade humana ${ }^{17}$. Atualmente, a eutanásia é considerada crime no Brasil ${ }^{2,17}$, sendo objeto de polêmicas e discussões que perpassam conflitos e valores relativos à vida e à dignidade humana ${ }^{17}$. Pelo fato de o Brasil ser Estado majoritariamente cristão, o discurso político-religioso exerce expressiva influência contra a adesão ou aceitação da eutanásia ${ }^{17}$.

O suicídio assistido é semelhantemente abordado. De mesma finalidade e indicação que a eutanásia, consiste em administrar intencionalmente medicamentos letais, seja pelo próprio paciente ou com auxílio de terceiros ${ }^{27}$. Tal conduta é descrita como crime no artigo 122 do Código Penal ${ }^{29}$, embora o direito de morrer esteja relacionado com a autonomia do indivíduo ${ }^{2}$. Nesse sentido, com base no $\S 1^{\circ}$ do artigo 121 do mesmo diploma ${ }^{29}$, é possível considerar a eutanásia espécie de homicídio privilegiado, motivado por relevante valor moral - o respeito à autonomia do indivíduo em decidir o momento de sua morte -, o que poderia reduzir a pena imposta.
Outro ponto a ser considerado é a sedação paliativa, que visa aliviar o sofrimento ao promover a redução da consciência, não apresentando, portanto, capacidade de prolongar ou encurtar a vida ${ }^{12}$. Segundo Santos e colaboradores, vale considerar a doença terminal como o estado mais degradante da essência humana, de forma que cada paciente deve ser tratado de maneira singular, segundo suas necessidades físicas, psicológicas $e$ espirituais ${ }^{38}$. Além disso, o aumento do sofrimento do paciente e a ausência de perspectiva de melhora muitas vezes gera expressivo gasto de recursos, além de causar angústia em familiares, profissionais e, especialmente, nos pacientes ${ }^{17}$.

O paciente pode exprimir seu desejo assistencial e terapêutico em documento jurídico para orientar as decisões quando for impossível reverter seu quadro clínico e ele não for capaz de exercer autodeterminação e autogoverno ${ }^{16,39}$. Trata-se do testamento vital, instrumento voltado a resguardar os direitos dos pacientes e as ações dos profissionais em situações peculiares ${ }^{16}$. A literatura aponta dualidade no objetivo desse dispositivo, podendo consistir tanto em meio de incentivar a eutanásia quanto apenas em forma de suspender procedimentos que não trarão benefícios óbvios ao paciente, obedecendo, desse modo, ao princípio da autonomia do indivíduo ${ }^{16}$.

O Conselho Federal de Medicina (CFM), por meio da Resolução $1.995 / 2012^{40}$, reconhece as diretivas antecipadas de vontade como documento válido e que resguarda o médico no seguimento de suas ações ${ }^{16}$. Entretanto, tal documento não é regulamentado pelo Código Civil ${ }^{41}$, o que aumenta a insegurança dos profissionais em aceitá-lo como forma de assistir o paciente ${ }^{16}$. Outro dilema ético envolvido com o testamento vital é a estabilidade da decisão do enfermo, uma vez que se fundamenta em constructo imaginário de como seria sua vida em momento futuro, sendo possível que mude de ideia quando de fato experimentar tal condição ${ }^{16}$.

Por fim, outro aspecto importante a ser tratado é a ressuscitação cardiopulmonar, que não deve ser realizada quando o paciente assina previamente termo denominado "Ordem de Não Reanimar" (ONR). Sua aceitação entre os pacientes é maior quando convivem com doenças graves e efeitos orgânicos intratáveis, como intensos processos álgicos, náuseas e fadiga. 
A elaboração da ONR também não é regulamentada no Brasil ${ }^{25}$, existindo apenas orientações éticas, como a Resolução CFM 1.805/2006 ${ }^{42}$ e o Código de Ética Médica ${ }^{43}$. Tais documentos não são específicos, o que justifica o desconhecimento dos participantes de uma pesquisa sobre o assunto ${ }^{25}$. Vale reafirmar que o desejo expresso do paciente deve ser considerado fator essencial para o seguimento das ações terapêuticas. Apesar disso, nem sempre os médicos permitem limitá-las, mesmo sendo a melhor forma de beneficiar o paciente ${ }^{25}$, o que fere os princípios de autonomia, beneficência e não maleficência.

\section{Tomada de decisões na saúde}

A bioética clínica envolve diversas temáticas relevantes para a tomada de decisão em saúde. Siqueira-Batista e colaboradores destacam, entre elas, dilemas relacionados a: (1) início da vida abortamento, tecnologias de reprodução assistida; (2) fim da vida - eutanásia, suicídio assistido, ordem de não reanimação, diretivas antecipadas, cuidados paliativos, distanásia, obstinação terapêutica, transplantes de órgãos (critério de morte, prioridade para acesso ao procedimento); (3) decisões diagnósticas, terapêuticas e profiláticas em caso de recusa do paciente ou de seu responsável legal; (4) sigilo, privacidade e confidencialidade de informações; e (5) alocação e gerenciamento de recursos escassos (ou "quem vai para o respirador?") ${ }^{44}$.

Evidencia-se que a conduta adotada nesses casos conflitivos e dilemáticos dependerá de minuciosa análise e da implementação das teorias da bioética, no intuito de direcionar as tomadas de decisão ${ }^{11}$. Além disso, os principais conflitos que envolvem o processo decisório entre profissionais da saúde, pacientes e familiares estão intimamente relacionados a valores, crenças e cultura ${ }^{12}$. Vale ressaltar que, às vezes, a complexidade laboral do processo saúde-doença submete os profissionais a escolhas contrárias a seus valores fundamentais, o que pode levar a sofrimento moral, com impacto nas dimensões psicológica, orgânica e social ${ }^{24}$.

A cautelosa e razoável tomada de decisão exige esclarecimento e consideração dos valores de cada indivíduo envolvido no processo, dado que inúmeras razões favorecem conflitos, como comunicação ausente ou insuficiente. Em decorrência disso, a falta de informação priva pacientes e familiares de conhecerem o real estado de saúde, os sofrimentos típicos da fase final da vida e as tecnologias terapêuticas disponíveis para minimizá-los ${ }^{12}$.

Não obstante, é válido ressaltar que, no âmbito da bioética clínica, a literatura divulga variados modelos para a tomada de decisão que sistematicamente delimitam, apreciam e apresentam propostas que visam solucionar conflitos bioéticos evidenciados na assistência individual a cada paciente ${ }^{11}$. Nessa perspectiva, o principialismo defende que o processo decisório deve respeitar estritamente seus preceitos, sem hierarquizá-los ${ }^{19}$.

\section{Considerações finais}

Observou-se que o discurso e as condutas bioéticas são fundamentais para nortear a assistência e os serviços de saúde, estando presentes em situações que abarcam do nascimento à morte do indivíduo. A bioética é identificada, portanto, como ferramenta imprescindível para a gestão em saúde. Quando empregada na assistência propriamente dita, a bioética possibilita atender às necessidades individuais de cada paciente, instruindo o direcionamento terapêutico de forma a evitar ou minimizar riscos e danos físicos, assim como conflitos éticos ou morais.

Além disso, constatou-se que a autonomia do paciente foi o princípio bioético mais abordado em diversas circunstâncias clínicas, especialmente nos dilemas relativos ao fim da vida, em que a capacidade de autogoverno nem sempre é absoluta e nem sempre encontra respaldo legal para seu exercício. Recomenda-se desenvolver mais estudos nessa temática, que merece outros olhares para que a reflexão seja constante e sempre atual, especialmente para aqueles profissionais que lidam diariamente com situações que envolvem o início e o fim da vida. 


\section{Referências}

1. Souza EV Jr, Silva VSB, Lozado YA, Bomfim ES, Alves JP, Boery EN, Boery RNSO. Dilemas bioéticos na assistência médica às gestantes adolescentes. Rev. bioét. (Impr.) [Internet]. 2018 [acesso 15 jan 2020];26(1):87-94. DOI: 10.1590/1983-80422018261229

2. Santos DA, Almeida ERP, Silva FF, Andrade LHC, Azevêdo LA, Neves NMBC. Reflexões bioéticas sobre a eutanásia a partir de caso paradigmático. Rev. bioét. (Impr.) [Internet]. 2014 [acesso 15 jan 2020];22(2):367-72. DOI: 10.1590/1983-80422014222018

3. Mapengo MAA, Sales-Peres SHC, Sales-Peres A. Bioethics criteria in dentistry research of humans. Rev Gaúcha Odontol [Internet]. 2018 [acesso 15 jan 2020];66(4):289-95. DOI: 10.1590/ 1981-863720180004000011295

4. Potter VR. Bioethics, the science of survival. Perspect Biol Med [Internet]. 1970 [acesso 24 fev 2021];14(1):127-53. DOI: $10.1353 / \mathrm{pbm} .1970 .0015$

5. Motta LCS, Oliveira LN, Silva EE, Siqueira-Batista R. Tomada de decisão em (bio)ética clínica: abordagens contemporâneas. Rev. bioét. (Impr.) [Internet]. 2016 [acesso 15 jan 2020];24(2):304-14. DOI: 10.1590/ 1983-80422016242131

6. Ercole FF, Melo LS, Alcoforado CLGC. Integrative review versus systematic review. Reme [Internet]. 2014 [acesso 15 jan 2020];18(1):12-4. DOI: 10.5935/1415-2762.20140001

7. Mendes KDS, Silveira RCCP, Galvão CM. Revisão integrativa: método de pesquisa para a incorporação de evidências na saúde e na enfermagem. Texto Contexto Enferm [Internet]. 2008 [acesso 15 jan 2020];17(4):758-64. DOI: 10.1590/S0104-07072008000400018

8. Bases de dados da coleção BVS. Portal Regional da BVS [Internet]. 2016 [acesso 15 jan 2020]. Disponível: https://bit.ly/2NK71Yf

9. Seoane AF, Fortes PAC. Percepção de médicos e enfermeiros de unidades de assistência médica ambulatorial sobre humanização nos serviços de saúde. Saúde Soc [Internet]. 2014 [acesso 15 jan 2020];23(4):1408-16. DOI: 10.1590/S0104-12902014000400023

10. Franco RS, Franco CAGS, Portilho EML, Cubas MR. O conceito de competência: uma análise do discurso docente. Rev Bras Educ Méd [Internet]. 2014 [acesso 15 jan 2020];38(2):173-81. DOI: 10.1590/ S0100-55022014000200003

11. Siqueira-Batista R, Gomes AP, Maia PM, Costa IT, Paiva AO, Cerqueira FR. Modelos de tomada de decisão em bioética clínica: apontamentos para a abordagem computacional. Rev. bioét. (Impr.) [Internet]. 2014 [acesso 15 jan 2020];22(3):456-61. DOI: 10.1590/1983-80422014223028

12. Eich M, Verdi MIM, Martins PPS. Deliberação moral em sedação paliativa para uma equipe de cuidados paliativos oncológicos. Rev. bioét. (Impr.) [Internet]. 2015 [acesso 15 jan 2020];23(3):583-92. DOI: 10.1590/1983-80422015233095

13. Gomes D, Ramos FRS. Solidariedade, aliança e comprometimento do profissional da saúde nas práticas do Sistema Único de Saúde (SUS): um debate bioético. Interface Comun Saúde Educ [Internet]. 2015 [acesso 15 jan 2020];19(52):9-20. DOI: 10.1590/1807-57622014.0412

14. Gracindo GCL. A moralidade das intervenções cirúrgicas com fins estéticos de acordo com a bioética principialista. Rev. bioét. (Impr.) [Internet]. 2015 [acesso 15 jan 2020];23(3):524-34. DOI: 10.1590/ 1983-80422015233089

15. Saito DYT, Zoboli ELCP. Cuidados paliativos e a atenção primária à saúde: scoping review. Rev. bioét. (Impr.) [Internet]. 2015 [acesso 15 jan 2020];23(3):593-7. DOI: 10.1590/1983-80422015233096

16. Chehuen Neto JA, Ferreira RE, Silva NCS, Delgado ÁHA, Tabet CCG, Almeida GG, Vieira IF. Testamento vital: o que pensam profissionais de saúde? Rev. bioét. (Impr.) [Internet]. 2015 [acesso 15 jan 2020];23(3):572-82. DOI: 10.1590/1983-80422015233094

17. Guimarães MM, Carvalho MAF, Simões IAR, Lima RS. Eutanásia e distanásia: percepção de médicos e enfermeiros de uma cidade sul mineira. Rev Enferm Uerj [Internet]. 2016 [acesso 15 jan 2020];24(2):e9545. DOI: $10.12957 /$ reuerj.2016.9545 
18. Outomuro D, Mirabile LM. Confidencialidad y privacidad en la medicina y en la investigación científica: desde la bioética a la ley. Rev. bioét. (Impr.) [Internet]. 2015 [acesso 15 jan 2020];23(2):238-43. DOI: 10.1590/1983-80422015232062

19. Nora CRD, Zoboli ELCP, Vieira MM. Deliberação ética em saúde: revisão integrativa da literatura. Rev. bioét. (Impr.) [Internet]. 2015 [acesso 15 jan 2020];23(1):114-23. DOI: 10.1590/1983-80422015231052

20. Marques Filho J, Hossne WS. A relação médico-paciente sob a influência do referencial bioético da autonomia. Rev. bioét. (Impr.) [Internet]. 2015 [acesso 15 jan 2020];23(2):304-10. DOI: 10.1590/ 1983-80422015232069

21. Riveros Ríos M. Aspectos bioéticos desde la visión personalista de la espiritualidad en el manejo de las personas en el área de la salud. An Fac Cienc Méd Asunción [Internet]. 2017 [acesso 15 jan 2020];50(1):25-50. DOI: 10.18004/anales/2017.050(01)25-050

22. Santos ACG, lamarino APM, Silva JB, Zollner ACR, Constantino CF. Considerações bioéticas sobre a relação médico-paciente indígena. Rev. bioét. (Impr.) [Internet]. 2017 [acesso 15 jan 2020];25(3):603-10. DOI: 10.1590/1983-80422017253217

23. Gomes AP, Gonçalves LL, Souza CR, Siqueira-Batista R. Estratégia Saúde da Família e bioética: grupos focais sobre trabalho e formação. Rev. bioét. (Impr.) [Internet]. 2016 [acesso 15 jan 2020];24(3):488-94. DOI: $10.1590 / 1983-80422016243148$

24. Fachini JS, Scrigni AV, Lima RCGS. Sofrimento moral de trabalhadores de uma UTI pediátrica. Rev. bioét. (Impr.) [Internet]. 2017 [acesso 15 jan 2020];25(1):111-22. DOI: 10.1590/1983-80422017251172

25. Eidt V, Bruneri GD, Bonamigo EL. Ordem de não reanimar sob a perspectiva de pacientes oncológicos e seus familiares. Mundo Saúde [Internet]. 2017 [acesso 15 jan 2020];41(3):395-403. DOI: 10.15343/ 0104-7809.20174103395403

26. Pirôpo US, Damasceno RO, Rosa RS, Sena ELS, Yarid SD, Boery RNSO. Interface do testamento vital com a bioética, atuação profissional e autonomia do paciente. Rev Salud Pública [Internet]. 2018 [acesso 15 jan 2020];20(4):505-10. DOI: 10.15446/rsap.v20n4.65009

27. Brandalise VB, Remor AP, Carvalho D, Bonamigo EL. Suicídio assistido e eutanásia na perspectiva de profissionais e acadêmicos de um hospital universitário. Rev. bioét. (Impr.) [Internet]. 2018 [acesso 15 jan 2020];26(2):217-27. DOI: 10.1590/1983-80422018262242

28. Conselho Nacional de Saúde. Resolução CNS n 510, de 7 de abril de 2016. Dispõe sobre as normas aplicáveis a pesquisas em ciências humanas e sociais cujos procedimentos metodológicos envolvam a utilização de dados diretamente obtidos com os participantes ou de informações identificáveis ou que possam acarretar riscos maiores do que os existentes na vida cotidiana. Diário Oficial da União [Internet]. Brasília, $\mathrm{n}^{\circ}$ 98, p. 44, 24 maio 2016 [acesso 18 fev 2021]. Seção 1. Disponível: https://bit.ly/2NBBYOv

29. Brasil. Decreto-Lei $n^{\circ}$ 2.848, de 7 de dezembro de 1940. Código Penal. Diário Oficial da União [Internet]. Brasília, $31 \mathrm{dez} 1940$ [acesso 24 fev 2021]. Disponível: http://bit.ly/18kAHOG

30. Borgsteede SD, Deliens L, Van der Wal G, Francke AL, Stalman WAB, Van Eijk JTM. Interdisciplinary cooperation of GPs in palliative care at home: a nationwide survey in the Netherlands. Scand J Prim Health Care [Internet]. 2007 [acesso 15 jan 2020];25(4):226-31. DOI: 10.1080/02813430701706501

31. Brown $\mathrm{H}$, Johnston $\mathrm{B}$, Ostlund $\mathrm{U}$. Identifying care actions to conserve dignity in end-of-life care. $\mathrm{Br} \mathrm{J}$ Community Nurs [Internet]. 2011 [acesso 15 jan 2020];16(5):238-45. DOI: 10.12968/bjcn.2011.16.5.238

32. Lorenzo CFG. Desafios para uma bioética clínica interétnica: reflexões a partir da política nacional de saúde indígena. Rev. bioét. (Impr.) [Internet]. 2011 [acesso 15 jan 2020];19(2):329-42. Disponível: https://bit.ly/3raoqYz

33. Coa TF, Pettengill MAM. Autonomia da criança hospitalizada frente aos procedimentos: crenças da enfermeira pediatra. Acta Paul Enferm [Internet]. 2006 [acesso 4 dez 2020];19(4):433-8. DOI: 10.1590/ S0103-21002006000400011 
34. Conselho Nacional de Educação, Câmara de Educação Superior. Resolução CNE/CES n 3, de 20 de junho de 2014. Institui diretrizes curriculares nacionais do curso de graduação em medicina e dá outras providências. Diário Oficial da União [Internet]. Brasília, 23 jun 2014 [acesso 24 fev 2021]. Disponível: https://bit.ly/3bkwhOa

35. Gomes D, Ramos FRS. Op. cit. p. 19.

36. Zamorano Jiménez CA, Chirino-Barceló Y, Baptista González HA, Altamirano Bustamante MM. Bioética en tiempo real: el límite de la viabilidad en los recién nacidos. Méd UIS [Internet]. 2013 [acesso 15 jan 2020];26(3):23-31. Disponível: https://bit.ly/3tqn6Tw

37. Bacon F. Historia vitae et mortis. Rio de Janeiro: Vozes; 1963.

38. Santos DA, Almeida ERP, Silva FF, Andrade LHC, Azevêdo LA, Neves NMBC. Op. cit. p. 370.

39. Thompson AE. Advanced directives. Jama [Internet]. 2015 [acesso 15 jan 2020];313(8):868. DOI: 10.1001/ jama.2015.133

40. Conselho Federal de Medicina. Resolução CFM n 1.995, de 31 de agosto de 2012. Dispõe sobre as diretivas antecipadas de vontade dos pacientes. Diário Oficial da União [Internet]. Brasília, p. 269-70, 31 ago 2012 [acesso 15 jan 2020]. Seção 1. Disponível: https://bit.ly/39yuFj0

41. Brasil. Lei $n^{\circ} 10.406$, de 10 de janeiro de 2002. Institui o Código Civil. Diário Oficial da União [Internet]. Brasília, p. 1, 11 jan 2002 [acesso 15 jan 2020]. Disponível: https://bit.ly/3csbRnq

42. Conselho Federal de Medicina. Resolução CFM n 1.805, de 9 de novembro de 2006. Na fase terminal de enfermidades graves e incuráveis é permitido ao médico limitar ou suspender procedimentos e tratamentos que prolonguem a vida do doente, garantindo-lhe os cuidados necessários para aliviar os sintomas que levam ao sofrimento, na perspectiva de uma assistência integral, respeitada a vontade do paciente ou de seu representante legal. Diário Oficial da União [Internet]. Brasília, p. 169, 28 nov 2006 [acesso 15 jan 2020]. Seção 1. Disponível: https://bit.ly/39Ea7p6

43. Conselho Federal de Medicina. Código de Ética Médica: Resolução CFM n 1.391 , de 17 de setembro de 2009: versão de bolso. Brasília: Conselho Federal de Medicina; 2010.

44. Siqueira-Batista R, Gomes AP, Maia PM, Costa IT, Paiva AO, Cerqueira FR. Op. cit. p. 457. 
Edison Vitório de Souza Júnior - Doutorando - edison.vitorio@usp.br (D) 0000-0003-0457-0513

Gabriel Aguiar Nunes - Graduando - aguiar.gbn@gmail.com (D) $0000-0002-8738-2990$

Cristiane dos Santos Silva - Graduada - cristianeimic@gmail.com (ID) 0000-0003-3822-1397

Benedito Fernandes da Silva Filho - Mestre - ditofilho13@gmail.com (D) 0000-0003-2464-9958

Poliana Souza Lapa - Graduada - posolapa@yahoo.com.br (D) 0000-0002-9262-7745

Paloma Dias Duarte - Graduanda - palomaduarte1981@outlook.com

(D) 0000-0001-9556-878X

Eduardo Nagib Boery - Doutor - eduardoboery@gmail.com (D) 0000-0001-7624-4405

Rita Narriman Silva de Oliveira Boery - Doutora - rboery@gmail.com

(D) 0000-0002-7823-9498

Namie Okino Sawada - Livre-docente - namie.sawada@unifal-mg.edu.br (D) 0000-0002-1874-3481

Correspondência

Edison Vitório de Souza Júnior - Av. dos Bandeirantes, 3.900, Campus Universitário, Monte Alegre CEP 14040-902. Ribeirão Preto/SP, Brasil.

\section{Participação dos autores}

Edison Vitório de Souza Júnior, Gabriel Aguiar Nunes e Cristiane dos Santos Silva delinearam o estudo, coletaram os dados e, com Benedito Fernandes da Silva Filho, Poliana Souza Lapa e Paloma Dias Duarte, redigiram o manuscrito e discutiram os resultados. Eduardo Nagib Boery, Rita Narriman Silva de Oliveira Boery e Namie Okino Sawada realizaram a revisão crítica do manuscrito, ajustaram seu conteúdo científico e aprovaram a versão final.

Recebido: 11.8 .2019

Revisado: 30.11 .2020

Aprovado: 4.12 .2020 